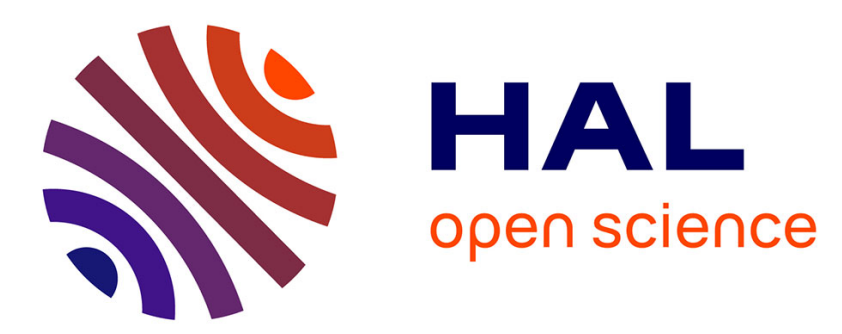

\title{
Borrowing Constraints and International Risk Sharing: Evidence from Asymmetric Error-Correction
}

\author{
Markus Leibrecht, Johann Scharler
}

\section{To cite this version:}

Markus Leibrecht, Johann Scharler. Borrowing Constraints and International Risk Sharing: Evidence from Asymmetric Error-Correction. Applied Economics, 2010, pp.1. 10.1080/00036840903103692 . hal-00582305

\section{HAL Id: hal-00582305 \\ https://hal.science/hal-00582305}

Submitted on 1 Apr 2011

HAL is a multi-disciplinary open access archive for the deposit and dissemination of scientific research documents, whether they are published or not. The documents may come from teaching and research institutions in France or abroad, or from public or private research centers.
L'archive ouverte pluridisciplinaire HAL, est destinée au dépôt et à la diffusion de documents scientifiques de niveau recherche, publiés ou non, émanant des établissements d'enseignement et de recherche français ou étrangers, des laboratoires publics ou privés. 


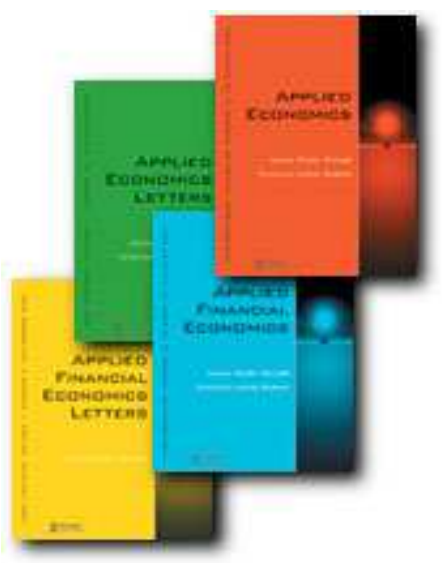

\section{Borrowing Constraints and International Risk Sharing: Evidence from Asymmetric Error-Correction}

\begin{tabular}{|r|l|}
\hline Journal: & Applied Economics \\
\hline Manuscript ID: & APE-08-0236.R1 \\
\hline Journal Selection: & Applied Economics \\
\hline $\begin{array}{r}\text { Date Submitted by the } \\
\text { Author: }\end{array}$ & 26-Nov-2008 \\
\hline Complete List of Authors: & $\begin{array}{l}\text { Leibrecht, Markus; University of Economics and BA, Research } \\
\text { Institute "International Tax Coordination" } \\
\text { Scharler, Johann; University of Linz, Department of Economics }\end{array}$ \\
\hline JEL Code: & $\begin{array}{l}\text { F36 - Financial Aspects of Economic Integration < F3 - International } \\
\text { Finance < F - International Economics, F41 - Open Economy } \\
\text { Macroeconomics < F00 - General < FO - General < F - International } \\
\text { Economics }\end{array}$ \\
\hline Keywords: & International Risk Sharing, Error-Correction \\
\hline & \multicolumn{2}{|l}{} \\
\hline
\end{tabular}

\section{今 scholaronE" \\ Manuscript Central}




\title{
Borrowing Constraints and International Risk
} Sharing: Evidence from Asymmetric Error-Correction

\author{
Markus Leibrecht* Johann Scharler ${ }^{\dagger}$
}

March 2008

\begin{abstract}
We analyze the adjustment process of consumption growth after disequilibrating output shocks in a sample of OECD countries. In particular, we test the hypothesis that consumption is smoothed to a lesser degree after negative shocks, whereas the impact of a positive shocks is delayed for a longer period of time. Our analysis is based on an error-correction framework that allows for asymmetric adjustment. We find that the mean adjustment lag after a negative shock is 6.5 years compared to 10.5 years after a positive shock. This result is consistent with the interpretation that borrowing constraints limit the degree to which the impact of negative shocks on consumption can be smoothed.
\end{abstract}

Keywords: International Risk Sharing, Error-Correction JEL codes: F36, F41

\footnotetext{
${ }^{*}$ Corresponding author; Vienna University of Economics and Business Administration, Department of Economics, Augasse 2 - 6, A-1090 Vienna, Austria, Phone (+43-1) 313 36-4264, Fax (+43-1) 313 36-9203, e-mail: markus.leibrecht@wu-wien.ac.at.

${ }^{\dagger}$ University of Linz, Department of Economics, Altenbergerstrasse 69, A-4040 Linz, Austria, Phone (+43-0) 732-2468-8360, Fax (+43-0) 732-2468-9679, e-mail: Johann.Scharler@jku.at.
} 


\section{Introduction}

By holding internationally diversified portfolios, agents should be able to pool country-specific risks and thereby reduce the impact of output fluctuations to some extent. The empirical literature on international risk sharing shows rather convincingly that the degree to which idiosyncratic risk is diversified internationally is low (see e.g. Obstfeld and Rogoff, 2000; Lewis, 1999; Obstfeld, 1994; Backus et al., 1992). ${ }^{1}$

The sources of this lack of international risk sharing are not yet fully understood. ${ }^{2}$ Sørensen and Yosha (1999) find that international risk sharing among countries occurs to a large extent through international borrowing and lending. That is, after a country-specific shock, countries adjust their net asset positions to smooth the impact of the shock. However, this type of consumption smoothing may be prevented to some extent if countries face borrowing constraints on international financial markets. In this case it may not be possible to borrow sufficient amounts to smooth the impact of a negative shock. Moreover, even if countries are able to borrow, they may not be able to sustain a negative net foreign asset position for longer periods of time. In contrast, the impact of positive shocks can be delayed for a longer period of time via international lending. Thus, if countries face borrowing constraints on the adjustment of their net foreign asset position, then we expect that consumption responds stronger and also sooner to adverse shocks. This implies that constraints on international financial markets may not only lead to a low degree of risk sharing but also to an asymmetric adjustment process after disequilibrating output shocks depending on the sign of these shocks.

\footnotetext{
${ }^{1}$ A related branch of the literature studies risk sharing within countries (e.g Asdrubali et al., 1996; Scorcu, 1998; Buettner, 2002; Borge and Matsen, 2004).

${ }^{2}$ Several Explanations have been proposed in the literature. See e.g. Backus et al. (1992), Obstfeld (1994), Lewis (1996), Stockman and Tesar (1995), Baxter and Crucini (1995), Imbs (2006) and Hoffmann (2008).
} 
In this paper we focus on this adjustment process back to the longrun relationship and test the hypothesis that the impact of negative output shocks on consumption can be smoothed to a lesser degree than the impact of positive shocks. Although the literature documents and provides explanations for the low degree of international consumption risk sharing it is rather silent concerning the adjustment process after shocks to output. Thus, we contribute to the literature in this respect and document a further role of borrowing constraints besides their relevance for the level of risk sharing.

Our analysis is based on a bivariate error-correction model (ECM) framework, which allows us not only to estimate the degree of international risk sharing in the long-run but also the speed-of-adjustment back to the longrun relationship. To study asymmetries we allow the speed-of-adjustment coefficients to depend on the sign and also the size of disequilibrating shocks.

We find that the mean adjustment lag after a negative output shock is 6.5 years compared to 10.5 years after a positive shock. Hence, the adjustment of consumption growth to output shocks is indeed asymmetric: countries can smooth the impact of adverse shocks on consumption for a shorter period than the impact of positive shocks. This result is consistent with the interpretation that borrowing constraints become binding relatively quickly after negative shocks and thereby reduce a country's ability to smooth consumption.

The paper is closely related to the literature that investigates the degree of risk sharing at different time horizons (see e.g. Becker and Hoffmann, 2006; Artis and Hoffmann, 2004; Canova and Ravn, 1996). These studies typically argue that the observed lack of international risk sharing may be due to a lack of insurance against permanent shocks. In contrast to our paper, this branch of the literature does not explicitly take the adjustment process into account. Methodologically, our analysis is also related to the literature that distinguishes between positive and negative changes in output to investigate 
the role of borrowing constraints in the context of the permanent output hypothesis (Shea, 1995a,b; Altonji and Siow, 1987).

The remainder of the paper is structured as follows: Section 2 outlines the empirical methodology which forms the basis of our analysis. Section 3 is devoted to data and estimation results while section 4 summarizes and concludes the paper.

\section{Empirical Model and Methodology}

As it is standard in the literature we rely on a measure of risk sharing based on the benchmark of complete markets. If markets are complete, then consumption should be (i) highly correlated across countries and (ii) not be influenced by any idiosyncratic variables, as for instance output (see Asdrubali et al., 1996; Sørensen and Yosha, 1999). Formally: $\log c_{i t}=$ $\alpha_{i}+\log c_{t}$, where $c_{i t}$ denotes real per capita consumption at time $t$ in country $i, c_{t}$ is aggregate consumption, which is defined as a population weighted average over all relevant countries, and $\alpha_{i}$ are country-specific time-invariant effects. If country-specific risks are not perfectly pooled across countries, then consumption will track idiosyncratic or country-specific income, $\tilde{y}_{i t}=$ $\log y_{i t}-\log y_{t}$, where $y_{i t}$ is real per capita output in country $i$ and $y_{t}$ is aggregate output. Thus, we obtain

$$
\tilde{c}_{i t}=\alpha_{i}+\beta \tilde{y}_{i t}
$$

where $\tilde{c}_{i t}=\log c_{1 t}-\log c_{t}$. Note that (1) represents a long-run relationship and therefore the dynamics of $\tilde{c}_{i t}$ and $\tilde{y}_{i t}$ can be expressed in terms of an ECM.

As noted, if countries face constraints on the adjustment of their foreign asset holdings, then the adjustment of consumption may be asymmetric after shocks to output. Specifically, running a negative net foreign asset position may only be possible in the short run and therefore consumption 
is likely to adjust quicker after adverse shocks. In our framework this hypothesis translates into asymmetric error-correction. We interpret periods of below average output growth as periods when adverse shocks have occurred. Similarly, periods of positive shocks correspond to above average output growth rates. To model this asymmetry, we introduce two dummy variables capturing positive, $D_{i t}^{+}$, and negative, $D_{i t}^{-}$, deviations from average output growth. Specifically, these dummies are defined as: $D_{i t}^{+}=1$ if $\Delta \tilde{y}_{i t}>\Delta \tilde{y}_{i .}$ and $D_{i t}^{+}=0$ otherwise, where $\Delta \tilde{y}_{i .}=\frac{1}{T} \sum_{i=1}^{T} \Delta \tilde{y}_{i t}$ is the mean change in $\Delta \tilde{y}_{i t}$ over the sample period for each country. Similarly, $D_{i t}^{-}=1$ if $\Delta \tilde{y}_{i t}<\Delta \tilde{y}_{i .}$ and $D_{i t}^{-}=0$ otherwise.

Taking the potential asymmetry in the adjustment process into account, we estimate a bivariate ECM of the following type:

$$
\begin{aligned}
& \Delta \tilde{c}_{i t}=\gamma_{10}+\gamma_{11} \Delta \tilde{y}_{i t-1}+\gamma_{12} \Delta \tilde{c}_{i t-1}+\lambda_{c}\left(\tilde{c}_{i t-1}-\alpha_{i}-\beta \tilde{y}_{i t-1}\right)+e_{1 i t}, \\
& \Delta \tilde{y}_{i t}=\gamma_{20}+\gamma_{21} \Delta \tilde{c}_{i t-1}+\gamma_{22} \Delta \tilde{y}_{i t-1}+\lambda_{y}\left(\tilde{c}_{i t-1}-\alpha_{i}-\beta \tilde{y}_{i t-1}\right)+e_{2 i t},
\end{aligned}
$$

where $\lambda_{k}=\lambda_{k}^{-} D_{i t}^{-}+\lambda_{k}^{+} D_{i t}^{+}$, for $k=c, y$, denotes the speed-of-adjustment coefficients depending on the sign the deviation from average output growth. Symmetric adjustment occurs if $\lambda_{c}^{-}$and $\lambda_{c}^{+}$have the same signs and $\left|\lambda_{c}^{-}\right|=$ $\left|\lambda_{c}^{+}\right|$. If borrowing constraints limit the degree to which consumption can be smoothed, then negative output shocks should be mirrored in consumption sooner than positive shocks and therefore we expect $\left|\lambda_{c}^{-}\right|>\left|\lambda_{c}^{+}\right|$in this case.

Furthermore, if borrowing constraints limit the amount of consumption smoothing after negative shocks then it appears conceivable that consumption is particularly exposed to large adverse shocks. That is, constraints may be particularly tight if countries have to borrow large amounts. To capture this idea, we introduce an additional set of dummy variables which take the size of the deviation from average output growth into account: $S_{i t}^{0}=1$ if $\Delta \tilde{y}_{i .}-\sigma<\Delta \tilde{y}_{i t}<\Delta \tilde{y}_{i .}+\sigma$ and $S_{i t}^{0}=0$ otherwise, where $\Delta \tilde{y}_{i}$. is the average change in idiosyncratic output in country $i$ and $\sigma$ its standard deviation 
over the sample period. Similarly, $S_{i t}^{-}=1$ if $\Delta \tilde{y}_{i t}<\Delta \tilde{y}_{i}-\sigma$ and $S_{i t}^{-}=0$ otherwise, and $S_{i t}^{+}=1$ if $\Delta \tilde{y}_{i t}>\Delta \tilde{y}_{i}+\sigma$ and $S_{i t}^{+}=0$ otherwise. Thus, this set of dummy variables distinguishes between times of roughly average or normal output growth and episodes of relatively low and high growth, where we consider values of $\Delta \tilde{y}_{i t}$ which fall within one standard deviation from the average change as normal. ${ }^{3}$

Note that our framework is targeted at the analysis of asymmetries in the adjustment process, but not of the level of risk sharing itself. This is the case as the dummy variables we introduce are defined with respect to short-run deviations from average growth. Hence, this classification cannot be used to separate countries according to the level of risk sharing they can achieve in the long run. Therefore, we restrict the $\beta$ coefficient in (1) to be the same in all countries. This assumption is justified as the Hausman-test carried out by Leibrecht and Scharler (2008), using the same data and same specification, does not reject the null hypothesis of a common long-run degree of international consumption risk sharing. Intuitively, the homogeneity with respect to $\beta$ is consistent with the interpretation that in the long run restrictions that may limit the amount of risk sharing have rather similar implications across countries.

To empirically implement (2) we follow the methodology outlined in Engle and Granger (1987). First, we estimate the long-run relationship in (1), and second, we estimate (2) and (3) by Seemingly Unrelated Regressions. ${ }^{4}$ A 'general-to-specific'- approach is used to derive a parsimonious model. We thereby apply the sequential general-to-specific testing strategy proposed by

\footnotetext{
${ }^{3}$ In principle, we can also identify periods characterized by more extreme deviations by using e.g. two standard deviations. However, since such periods rarely occur, we would not have enough observations.

${ }^{4}$ Our approach requires the series to be cointegrated. Since evidence in favor of cointegration has already been reported in Leibrecht and Scharler (2008) for our data set, we start directly with the estimation of the ECM.
} 
Hall (1994) and recommended by Maddala and Kim (1998) to each single equation and each variable. We start with a lag of $T^{1 / 3}$ (see Said and Dickey, 1984), which implies that the maximum number of lags is 4 in our case, and test down until the lag is statistically significant at the 10 percent level. ${ }^{5}$

\section{Data and Estimation Results}

\subsection{Data Description}

In our analysis, we include 21 OECD countries: Australia, Austria, Belgium, Canada, Denmark, Finland, France, Greece, Ireland, Italy, Japan, Luxembourg, the Netherlands, Norway, New Zealand, Portugal, Spain, Sweden, Switzerland, the UK and the US. The remaining OECD countries are not included due to limited data availability. Data are annual and range from 1951 to 2000. All series are obtained from the Penn World Table, release 6.1 by Heston et al. (2002). We use real per capita consumption and real per capita GDP measured in constant (1996) international prices as proxies for $\tilde{c}_{i t}$ and $\tilde{y_{i t}}$. World aggregates are calculated as weighted averages: $y_{t}=\sum_{i=1 \neq j}^{21} w_{i t} y_{i t}$ and $c_{t}=\sum_{i=1 \neq j}^{21} w_{i t} c_{i t}$, with $w_{i t}=p_{o p} p_{i t} / \sum_{i=1 \neq j}^{21} p o p_{i t}$, where pop $_{i t}$ denotes population. Thus, $c_{i t}$ and $y_{i t}$ themselves are not included in the world aggregate.

Table 1 provides an overview of the deviations from average output growth in our sample. Columns 2 and 3 of the table show the number of years characterized by above and below average output growth which correspond to the definitions of $D_{i t}^{+}$and $D_{i t}^{-}$. The remaining columns correspond to the definitions of $S_{i t}^{0}, S_{i t}^{-}$and $S_{i t}^{+}$.

Not surprisingly, the first two columns show that the numbers of above and below average growth rates are rather balanced. Moreover, years with

\footnotetext{
${ }^{5}$ Note, that we use the same number of observations to compare models with different lag length. The common number of observations used is 945 , which is the number of observations in case of lag $=4$, the maximum lag length we start with.
} 
above and below average output growth are experienced at the end of our sample period. Notable exceptions are on the one hand Ireland, Finland and the United States were the last episodes of below average growth rates were experienced in earlier years, indicating the relatively favorable macroeconomic performance of these countries in the last years. On the other hand Italy and Japan saw their last above average growth rates in 1995 and 1991, respectively, which corresponds to the weak performance these two countries experienced in the second half of the 1990s. From the last three columns we see that the vast majority of years represent 'normal' output growth, whereas periods where growth is at least one standard deviation above or below the average occur relatively rarely. Thus, the definitions of $S_{i t}^{-}$and $S_{i t}^{+}$ capture rather extreme events. Such extreme events occurred, for instance, in the Scandinavian countries (Denmark, Sweden and Finland) which experienced severe economic downturns around 1990. Ireland and Luxembourg, in contrast, experienced relatively high growth rates in the late 1990s, which may be due to substantial gains from the European common market.

[Table 1 here ]

\section{$3.2 \quad$ Results}

Table 2 shows the estimated parameters of the long-run relationship (1). We see that $\tilde{y}_{i t}$ enters strongly significantly with a point estimate of 0.904 . As discussed in Asdrubali et al. (1996) such an estimate implies that only around 10 percent of idiosyncratic risks are pooled in the long run. Thus, we find that long-run risk sharing is rather limited, which is in line with the literature cited above.

[Table 2 here]

Next, we estimate the ECM in (2) - (3). The testing down procedure 
shows that relatively parsimonious models are sufficient to capture the shortrun dynamics. The results based on our final specification are reported in Table 3. The top panel of the table shows the estimation results for the consumption equation (2). First of all, we see that $\Delta \tilde{c}_{i t}$ responds significantly to $\Delta \tilde{y}_{i t-1}$ which is inconsistent with perfect risk sharing since any influence of idiosyncratic variables - even lagged - should be completely eliminated under perfect risk sharing.

What we are primarily interest in are the speed-of-adjustment coefficients in the consumption equation. From Table 3 we see that the point estimates for $\lambda_{c}^{+}$and $\lambda_{c}^{-}$are both significantly negative which shows that consumption growth reacts to deviations from the long-run relationship in times of below and also above average output growth. Comparing the magnitudes of the estimated speed-of-adjustment coefficients shows that $\tilde{c}_{i t}$ reacts more strongly to deviations from the long-run relationship when output growth is below average output growth. In this case, the estimated speed-of-adjustment coefficient is -0.150 . In the case that $\Delta \tilde{y}_{i t}>\Delta \tilde{y}_{i}$, we estimate the speed of adjustment coefficient to be -0.094 . Furthermore, the null hypothesis of equal speed-of-adjustment coefficients for positive and negative deviations is rejected at the 10 percent level. The estimates imply mean adjustment lags of about 6.5 and 10.5 years. $^{6}$

Thus, the ordering of the estimated speed-of-adjustment coefficients is consistent with our hypothesis that borrowing constraints become binding soon after negative shocks. ${ }^{7}$ Intuitively, when countries experience adverse

\footnotetext{
${ }^{6}$ The mean adjustment lags are calculated as $1 /\left|\lambda_{c}^{+}\right|$and $1 /\left|\lambda_{c}^{-}\right|$, respectively.

${ }^{7}$ Note that symmetric adjustment is not necessarily inconsistent with the existence of borrowing constraints. Consider a country that experiences a positive shock. To smooth the impact of the shock, this country can lend to other countries. However, if all or most other countries face credit constraints, then this may not be possible. Hence, the response to the positive shock would be similar to the response to a negative shock. Thus, symmetric adjustment also indicate that almost all countries in the sample face constraints. However, given our results, this case does not appear to be relevant empirically.
} 
shocks to their idiosyncratic output growth rates, then their consumption growth mirrors output growth closely already after a relatively short period of time. The lower panel of Table 3 shows the results for the output equation (3). We see that three of its own lags are sufficient to capture the short run dynamics of idiosyncratic output growth $\Delta \tilde{y}_{i t}$. The table also shows that the response of $\Delta \tilde{y}_{i t}$ is only significantly different from zero in the case of positive deviations. Nevertheless the null that $\lambda_{y}^{-}=\lambda_{y}^{+}=0$ is rejected at the 10 percent level. Hence, $\Delta \tilde{y}_{i t}$ cannot be considered to be weakly exogenous in our system. Thus, consumption as well as output respond to shocks to restore the long-run relationship. Note that direct convergence to the long-run relationship occurs if $\lambda_{c}$ is negative and $\lambda_{y}$ is positive. We find, however, that $\lambda_{y}^{+}$turns out to be significantly below zero. Nevertheless, the system is stable since $\left|\lambda_{c}\right|>\left|\lambda_{y}\right|$ (see Juselius, 2006). The absolute value of the sum of the speed-of-adjustment coefficients is by far larger in the consumption equation.

[Table 3 here]

Next, we characterize risk sharing not only according to the sign of the deviation from average output growth, but also according to the the size of the deviation. We re-estimate the ECM in (2) - (3) but now we parameterize $\lambda_{k}=\lambda_{k}^{-} S_{i t}^{-}+\lambda_{k}^{0} S_{i t}^{0}+\lambda_{k}^{+} S_{i t}^{+}$, for $k=c, y$.

Table 4 shows that we obtain the lowest speed-of-adjustment coefficient in the consumption equation of -0.216 for the case where output growth is at least one standard deviation below average output growth. For values of $\Delta \tilde{y}_{i t}$ which are close to the average $\Delta \tilde{y}_{i}$. we obtain a markedly higher speed-of-adjustment coefficient of -0.111 and therefore a slower adjustment of consumption growth. The slowest adjustment is implied by the estimate for $\lambda_{c}^{+}$of -0.097 which is associated with output growth rates which are at least one standard deviation above average output growth. Most im- 
portantly however, $\lambda_{c}^{-}$is significantly different from both, $\lambda_{c}^{+}$and $\lambda_{c}^{0}$. The implied mean adjustment lags are about 4.5, 9 and 10 years respectively. Experiencing a pronounced negative output shock results in a much faster return to the long-run equilibrium than experiencing a negative, yet 'normal', or a positive deviation from average growth. Thus, the ordering of the estimated speed-of-adjustment coefficients is again consistent with our hypothesis. Note also that our results imply that consumption growth responds rather similarly after marked positive shocks and in normal periods from both a substantive and a statistical viewpoint.

Turning to the results for the output equation in the lower panel of the table, we again see that $\Delta \tilde{y}_{i t}$ reacts significantly only in the case of positive deviations. As before, the null of joint insignificance of the speedof-adjustment coefficients in (3) is rejected and the system is stable.

[Table 4 here]

\section{Concluding Remarks}

In this paper we analyze whether the adjustment process of consumption growth after disequilibrating output shocks depends on the sign of the shock. We indeed find evidence in this respect. The long-run equilibrium is restored relatively quickly after adverse output shocks, whereas consumption growth adjusts slower after positive output shocks. Thus, countries are able to smooth the impact of adverse shocks only to a comparably limited extent. One explanation is that borrowing constraints on international financial markets reduce the opportunities to smooth adverse output effects.

It has to be pointed out that borrowing constraints are perhaps not the only source of asymmetric adjustment in consumption. However, since it is well documented in the literature that risk sharing occurs primarily via the 
adjustment of asset holdings, frictions on international credit markets that result in borrowing constraints are likely to play a non-negligible role.

\section{References}

Altonji, J. G., Siow, A., 1987. Testing the response of consumption to income changes with (noisy) panel data. The Quarterly Journal of Economics 102 (2), 293-328.

Artis, M. J., Hoffmann, M., 2004. Financial globalization, international business cycles and consumption risk sharing. CEPR Discussion Papers 4697.

Asdrubali, P., Sørensen, B. E., Yosha, O., 1996. Channels of interstate risk sharing: The United States 1963-1990. Quarterly Journal of Economics 111, 1081-1110.

Backus, D. K., Kehoe, P. J., Kydland, F. E., 1992. International real business cycles. Journal of Political Economy 100, 745-775.

Baxter, M., Crucini, M. J., 1995. Business cycles and the asset structure of foreign trade. International Economic Review 36, 821-854.

Becker, S. O., Hoffmann, M., 2006. Intra- and international risk-sharing in the short run and the long run. European Economic Review 50 (3), $777-806$.

Borge, L.-E., Matsen, E. M., 2004. Public employment and regional risk sharing. Scandinavian Journal of Economics 106 (2), 215-230.

Buettner, T., 2002. Fiscal federalism and interstate risk sharing: empirical evidence from Germany. Economics Letters 74, 195-202.

Canova, F., Ravn, M. O., 1996. International consumption risk sharing. International Economic Review 37, 573-601. 
Engle, R. F., Granger, C. W. J., 1987. Co-integration and error correction: Representation, estimation, and testing. Econometrica 55 (2), 251-276.

Hall, A., 1994. Testing for a unit root in time series with pretest data-based model selection. Journal of Business and Economic Statistics 12 (4), 461470.

Heston, A., Summers, R., Aten, B., 2002. Penn world table version 6.1. Center for International Comparisons at the University of Pennsylvania (CICUP).

Hoffmann, M., 2008. The lack of international consumption risk sharing: Can inflation differentials and trading costs help explain the puzzle? Open Economies Review 19 (2), 183-201.

Imbs, J., 2006. The real effects of financial integration. Journal of International Economics 68 (2), 296-324.

Juselius, K., 2006. The Cointegrated VAR Model: Methodology and Applications. Oxford University Press, Great Clarendon Street, Oxford.

Leibrecht, M., Scharler, J., 2008. International risk sharing in the OECD: Some evidence based on panel cointegration. Open Economies Review forthcoming.

Lewis, K., 1999. Trying to explain home bias in equities and consumption. Journal of Economic Literature XXXVII, 571-608.

Lewis, K. K., 1996. What can explain the apparent lack of international consumption risk sharing. Journal of Political Economy 104, 267-297.

Maddala, G., Kim, I.-M., 1998. Unit roots, Cointegration, and Structural Change. Cambridge University Press, Trumpington Street, Cambridge. 
Obstfeld, M., 1994. Are industrial-country consumption risks globally diversified? In: Leiderman, L., Razin, A. (Eds.), Capital mobility: the impact on consumption, investment and growth. Cambridge University Press, Cambridge.

Obstfeld, M., Rogoff, K., 2000. The six major puzzles in international macroeconomics. In: Bernanke, B. S., Rogoff, K. (Eds.), NBER Macroeconomic Annual 2000. MIT Press, Cambridge, Massachusetts.

Said, E., Dickey, D. A., 1984. Testing for unit roots in autoregressive-moving average models of unknown order. Biometrika 71 (3), 599-607.

Scorcu, A. E., 1998. Consumption risk-sharing in Italy. Applied Economics 30 (1), 407-414.

Shea, J., 1995a. Myopia, liquidity constraints, and aggregate consumption: A simple test. Journal of Money, Credit and Banking 27 (3), 798-805.

Shea, J., 1995b. Union contracts and the life-cycle/permanent-income hypothesis. American Economic Review 85 (1), 186-200.

Sørensen, B. E., Yosha, O., 1999. International risk sharing and European monetary unification. Journal of International Economics 45, 211-238.

Stockman, A. C., Tesar, L., 1995. Tastes and technology in a two-country model of the business cycle: explaining international comovements. American Economic Review 85, 168-185. 
Table 1: Deviations from average output growth

\begin{tabular}{rrrrrr}
\hline \hline & below & above & positive & negative & normal \\
\hline Australia & $22(2000)$ & $27(1999)$ & $3(1958)$ & $9(1990)$ & 37 \\
Austria & $28(2000)$ & $21(1998)$ & $7(1974)$ & $4(1984)$ & 38 \\
Belgium & $24(1998)$ & $25(2000)$ & $6(1991)$ & $8(1993)$ & 35 \\
Canada & $19(1996)$ & $30(2000)$ & $4(1999)$ & $11(1991)$ & 34 \\
Switzerland & $28(1999)$ & $21(2000)$ & $8(1989)$ & $4(1976)$ & 37 \\
Denmark & $29(1999)$ & $20(2000)$ & $11(1994)$ & $5(1989)$ & 33 \\
Spain & $23(2000)$ & $26(1999)$ & $4(1995)$ & $6(1996)$ & 39 \\
Finland & $23(1993)$ & $26(2000)$ & $7(1982)$ & $7(1992)$ & 35 \\
France & $28(2000)$ & $21(1998)$ & $9(1982)$ & $4(1993)$ & 36 \\
United Kingdom & $26(1999)$ & $23(2000)$ & $8(1994)$ & $5(1981)$ & 36 \\
Greece & $27(1999)$ & $22(2000)$ & $12(1975)$ & $7(1987)$ & 30 \\
Ireland & $23(1986)$ & $26(2000)$ & $8(2000)$ & $10(1986)$ & 31 \\
Italy & $24(2000)$ & $25(1995)$ & $8(1980)$ & $10(2000)$ & 31 \\
Japan & $25(2000)$ & $24(1991)$ & $9(1970)$ & $6(1999)$ & 34 \\
Luxembourg & $26(1996)$ & $23(2000)$ & $9(1997)$ & $5(1975)$ & 35 \\
Netherlands & $24(2000)$ & $25(1999)$ & $5(1991)$ & $6(1981)$ & 38 \\
Norway & $23(2000)$ & $26(1997)$ & $4(1993)$ & $10(1999)$ & 35 \\
New Zealand & $23(1998)$ & $26(2000)$ & $6(1991)$ & $5(1977)$ & 38 \\
Portugal & $24(2000)$ & $25(1999)$ & $6(1991)$ & $7(1994)$ & 36 \\
Sweden & $24(1997)$ & $25(2000)$ & $7(1982)$ & $8(1993)$ & 34 \\
United States & $23(1991)$ & $26(2000)$ & $2(1984)$ & $10(1981)$ & 37 \\
\hline \hline
\end{tabular}

Notes: The columns labeled 'below' and 'above' report the number of periods in which real per capita GDP growth was either below or above the average growth rate. In brackets we report the last year when a positive or negative deviation occurred. The columns labeled "positive', "negative" and "normal" report the number of years in which real per capita GDP growth was at least one standard deviation blow average growth, at least one standard deviation above average growth and within plus/minus one standard deviation of the average growth rate, respectively. In brackets, we report the last year when the respective deviation occurred.

Table 2: Long-run Relationship

\begin{tabular}{lccc}
\hline \hline & coef & sd & p-value \\
\hline const & 0.118 & 0.012 & 0.000 \\
$\tilde{y}_{i t}$ & 0.904 & 0.015 & 0.000 \\
\hline adj. $R^{2}$ & 0.949 & & \\
F-Test & & & 0.000 \\
obs & 1050 & & 0.000 \\
\hline \hline
\end{tabular}

Notes: Country dummies are jointly significant and therefore included in the estimation. 
Table 3: Asymmetric Error-Correction

\begin{tabular}{lccc}
\hline \hline Dep. Var.: $\Delta \tilde{c}_{i t}$ & coef & sd & p-value \\
\hline const & -0.005 & 0.005 & 0.327 \\
$\Delta \tilde{y}_{i t-1}$ & 0.104 & 0.041 & 0.011 \\
$\lambda_{c}^{+}$ & -0.094 & 0.023 & 0.000 \\
$\lambda_{c}^{-}$ & -0.150 & 0.023 & 0.000 \\
\hline obs & 966 & & \\
$H_{0}: \lambda_{c}^{+}=\lambda_{c}^{-}$ & & & 0.089 \\
\hline Dep. Var.: $\Delta \tilde{y}_{i t}$ & coef & sd & p-value \\
\hline const & -0.005 & 0.004 & 0.168 \\
$\Delta \tilde{y}_{i t-1}$ & 0.190 & 0.030 & 0.000 \\
$\Delta \tilde{y}_{i t-2}$ & -0.012 & 0.027 & 0.643 \\
$\Delta \tilde{y}_{i t-3}$ & 0.058 & 0.026 & 0.024 \\
$\lambda_{y}^{+}$ & -0.036 & 0.017 & 0.035 \\
$\lambda_{y}^{-}$ & -0.009 & 0.017 & 0.577 \\
\hline obs & 966 & & \\
$H_{0}: \lambda_{y}^{+}=\lambda_{y}^{-}=0$ & & & 0.091 \\
\hline \hline
\end{tabular}

Notes: The top panel of the table reports estimated coefficient for the error correction model with $\Delta \tilde{c}_{i t}$ as the dependent variable. The bottom panel reports the results for $\Delta \tilde{y}_{i t}$ as the dependent variable. Country dummies are jointly significant and therefore included in the estimation. 
Table 4: Asymmetric Error-Correction and Large Deviations

\begin{tabular}{lccc}
\hline \hline Dep. Var.: $\Delta \tilde{c}_{i t}$ & coef & sd & p-value \\
\hline const & -0.005 & 0.005 & 0.348 \\
$\Delta \tilde{y}_{i t-1}$ & 0.100 & 0.042 & 0.016 \\
$\lambda_{c}^{0}$ & -0.111 & 0.019 & 0.000 \\
$\lambda_{c}^{+}$ & -0.097 & 0.044 & 0.028 \\
$\lambda_{c}^{-}$ & -0.216 & 0.046 & 0.000 \\
\hline obs & 966 & & \\
$H_{0}: \lambda_{c}^{+}=\lambda_{c}^{-}$ & & & 0.062 \\
$H_{0}: \lambda_{c}^{0}=\lambda_{c}^{-}$ & & & 0.034 \\
\hline Dep.Var: $\Delta \tilde{y}_{i t}$ & coef & sd & p-value \\
\hline const & -0.005 & 0.004 & 0.164 \\
$\Delta \tilde{y}_{i t-1}$ & 0.185 & 0.031 & 0.000 \\
$\Delta \tilde{y}_{i t-2}$ & -0.011 & 0.026 & 0.678 \\
$\Delta \tilde{y}_{i t-3}$ & 0.058 & 0.026 & 0.024 \\
$\lambda_{y}^{0}$ & -0.019 & 0.014 & 0.177 \\
$\lambda_{y}^{+}$ & -0.072 & 0.033 & 0.027 \\
$\lambda_{y}^{-}$ & 0.008 & 0.033 & 0.822 \\
\hline obs & 966 & & \\
$H_{0}: \lambda_{y}^{+}=\lambda_{y}^{-}=\lambda_{y}^{0}=0$ & & & 0.078 \\
\hline \hline
\end{tabular}

Notes: The top panel of the table reports estimated coefficient for the error correction model with $\Delta \tilde{c}_{i t}$ as the dependent variable. The bottom panel reports the results for $\Delta \tilde{y}_{i t}$ as the dependent variable. Country dummies are jointly significant and therefore included in the estimation. 


\title{
Borrowing Constraints and International Risk Sharing: Evidence from Asymmetric Error-Correction
}

\author{
November 2008
}

\begin{abstract}
We analyze the adjustment process of consumption growth after disequilibrating output shocks in a sample of OECD countries. In particular, we test the hypothesis that consumption is smoothed to a lesser degree after negative shocks, whereas the impact of a positive shock is delayed for a longer period of time. Our analysis is based on an errorcorrection framework that allows for asymmetric adjustment. We find that the mean adjustment lag after a negative shock is significantly shorter than after a positive shock, especially since the beginning of the 1980s. This result is consistent with the interpretation that borrowing constraints limit the degree to which the impact of negative shocks on consumption can be smoothed.
\end{abstract}

Keywords: International Risk Sharing, Error-Correction JEL codes: F36, F41 


\section{Introduction}

By holding internationally diversified portfolios, agents should be able to pool country-specific risks and thereby reduce the impact of output fluctuations to some extent. The empirical literature on international risk sharing shows rather convincingly that the degree to which idiosyncratic risk is diversified internationally is low (see e.g. Obstfeld and Rogoff, 2000; Lewis, 1999; Obstfeld, 1994; Backus et al., 1992). ${ }^{1}$

The sources of this lack of international risk sharing are not yet fully understood. $^{2}$ Sørensen and Yosha (1999) find that international risk sharing among countries occurs to a large extent through international borrowing and lending. That is, after a country-specific shock, countries adjust their net asset positions to smooth the impact of the shock. However, this type of consumption smoothing may be prevented to some extent if countries face borrowing constraints on international financial markets. In this case it may not be possible to borrow sufficient amounts to smooth the impact of a negative shock. Moreover, even if countries are able to borrow, they may not be able to sustain a negative net foreign asset position for longer periods of time. In contrast, the impact of positive shocks can be delayed for a longer period of time via international lending. Thus, if countries face borrowing constraints on the adjustment of their net foreign asset position, then we expect that consumption responds stronger and also sooner to adverse shocks. This implies that constraints on international financial markets may not only lead to a low degree of risk sharing but also to an asymmetric adjustment process after disequilibrating output shocks depending on the sign of these shocks.

In this paper we focus on this adjustment process back to the long-

\footnotetext{
${ }^{1}$ A related branch of the literature studies risk sharing within countries (e.g Asdrubali et al., 1996; Scorcu, 1998; Buettner, 2002; Borge and Matsen, 2004).

${ }^{2}$ Several Explanations have been proposed in the literature. See e.g. Backus et al. (1992), Obstfeld (1994), Lewis (1996), Stockman and Tesar (1995), Baxter and Crucini (1995), Imbs (2006) and Hoffmann (2008).
} 
run relationship and test the hypothesis that the impact of negative output shocks on consumption can be smoothed to a lesser degree than the impact of positive shocks. Although the literature documents and provides explanations for the low degree of international consumption risk sharing it is rather silent concerning the adjustment process after shocks to output. Thus, we contribute to the literature in this respect and document a further role of borrowing constraints besides their relevance for the level of risk sharing.

Our analysis is based on a bivariate error-correction model (ECM) framework, which allows us to estimate not only the degree of international risk sharing in the long-run but also the speed-of-adjustment back to the longrun relationship. To study asymmetries we allow the speed-of-adjustment coefficients to depend on the sign and also the size of disequilibrating shocks.

We find that the adjustment occurs significantly faster in case of negative shocks. Hence, the adjustment of consumption growth to output shocks is indeed asymmetric: countries can smooth the impact of adverse shocks on consumption for a shorter period of time than the impact of positive shocks. This result is consistent with the interpretation that borrowing constraints become binding relatively quickly after negative shocks and thereby reduce a country's ability to smooth consumption.

The paper is closely related to the literature that investigates the degree of risk sharing at different time horizons (see e.g. Becker and Hoffmann, 2006; Artis and Hoffmann, 2008; Canova and Ravn, 1996). These studies typically argue that the observed lack of international risk sharing may be due to a lack of insurance against permanent shocks. In contrast to our paper, this branch of the literature does not explicitly take the adjustment process into account. Methodologically, our analysis is also related to the literature that distinguishes between positive and negative changes in output to investigate the role of borrowing constraints in the context of the permanent income hypothesis (Shea, 1995a,b; Altonji and Siow, 1987). 
The remainder of the paper is structured as follows: Section 2 outlines the empirical methodology which forms the basis of our analysis. Section 3 is devoted to data and estimation results while section 4 summarizes and concludes the paper.

\section{Empirical Model and Methodology}

As it is standard in the literature we rely on a measure of risk sharing based on the benchmark of complete markets. If markets are complete, then consumption should be (i) highly correlated across countries and (ii) not be influenced by any idiosyncratic variables, as for instance output (see Asdrubali et al., 1996; Sørensen and Yosha, 1999).

Formally, assuming constant relative risk aversion utility functions, an efficient allocation is characterized by: $\log c_{i t}=\alpha_{i}+\log c_{t}$, where $c_{i t}$ denotes real per capita consumption at time $t$ in country $i, c_{t}$ is aggregate consumption, which is defined as a population weighted average over all relevant countries, and $\alpha_{i}$ are country-specific time-invariant effects. If country-specific risks are not perfectly pooled across countries, then consumption will track idiosyncratic or country-specific income, $\tilde{y}_{i t}=\log y_{i t}-\log y_{t}$, where $y_{i t}$ is real per capita output in country $i$ and $y_{t}$ is aggregate output. Thus, we obtain

$$
\tilde{c}_{i t}=\alpha_{i}+\beta \tilde{y}_{i t}
$$

where $\tilde{c}_{i t}=\log c_{1 t}-\log c_{t}$. Note that (1) represents a long-run relationship and therefore the dynamics of $\tilde{c}_{i t}$ and $\tilde{y}_{i t}$ can be expressed in terms of an ECM.

As briefly mentioned above, our analysis is based on the idea that constraints on the adjustment of foreign asset holdings give rise to asymmetric adjustment processes. Specifically, running a negative net foreign asset position may only be possible over a rather short period of time. Therefore consumption is likely to adjust quicker after adverse shocks. Thus, if risk 
sharing is indeed limited by binding borrowing constraints, then we expect to observe that consumption reacts faster to negative movements in output.

Note that although an asymmetric adjustment indicates that countries face borrowing constraints, a symmetric adjustment does not imply that borrowing constraints are absent or not binding. Consider the extreme case of autarky, where countries have no access to international financial markets and are therefore confined to consume their outputs in every period. By definition, this situation corresponds to a complete lack of international risk sharing and consumption perfectly tracks income in each country. It follows that the adjustment of consumption is necessarily symmetric, regardless of the sign of any shocks that lead to movements in output. Thus, although countries face extremely severe constraints in the sense that they are completely unable to participate on international financial markets, the adjustment process is still symmetric.

Even if we consider less extreme situations, symmetric adjustment may still be consistent with the existence of borrowing constraints. Consider a country that experiences a positive shock. To smooth the impact of the shock, this country can lend to other countries. However, if all or most other countries face credit constraints, then this may not be possible. Hence, the response to the positive shock would be similar to the response to a negative shock. Thus, symmetric adjustment may also indicate that almost all countries in the sample face constraints.

In short, although an asymmetric adjustment is consistent with the interpretation that countries face borrowing constraints on international financial markets, a symmetric adjustment process does not allow for an unambiguous interpretation.

In our estimation framework, asymmetric adjustment due to constraints translates into asymmetric error-correction. We interpret periods of below average output growth as periods when adverse shocks have occurred. Sim- 
ilarly, periods of positive shocks correspond to above average output growth rates. To model this asymmetry, we introduce two dummy variables capturing positive, $D_{i t}^{+}$, and negative, $D_{i t}^{-}$, deviations from average output growth. Specifically, these dummies are defined as: $D_{i t}^{+}=1$ if $\Delta \tilde{y}_{i t}>\Delta \tilde{y}_{i}$ and $D_{i t}^{+}=0$ otherwise, where $\Delta \tilde{y}_{i .}=\frac{1}{T} \sum_{i=1}^{T} \Delta \tilde{y}_{i t}$ is the mean change in $\Delta \tilde{y}_{i t}$ over the sample period for each country. Similarly, $D_{i t}^{-}=1$ if $\Delta \tilde{y}_{i t}<\Delta \tilde{y}_{i}$. and $D_{i t}^{-}=0$ otherwise.

Taking the potential asymmetry in the adjustment process into account, we estimate a bivariate ECM of the following type:

$$
\begin{aligned}
& \Delta \tilde{c}_{i t}=\gamma_{10}+\gamma_{11} \Delta \tilde{y}_{i t-1}+\gamma_{12} \Delta \tilde{c}_{i t-1}+\lambda_{c}\left(\tilde{c}_{i t-1}-\alpha_{i}-\beta \tilde{y}_{i t-1}\right)+e_{1 i t}, \\
& \Delta \tilde{y}_{i t}=\gamma_{20}+\gamma_{21} \Delta \tilde{c}_{i t-1}+\gamma_{22} \Delta \tilde{y}_{i t-1}+\lambda_{y}\left(\tilde{c}_{i t-1}-\alpha_{i}-\beta \tilde{y}_{i t-1}\right)+e_{2 i t},
\end{aligned}
$$

where $\lambda_{k}=\lambda_{k}^{-} D_{i t}^{-}+\lambda_{k}^{+} D_{i t}^{+}$, for $k=c, y$, denotes the speed-of-adjustment coefficients depending on the sign the deviation from average output growth. Symmetric adjustment occurs if $\lambda_{c}^{-}$and $\lambda_{c}^{+}$have the same signs and $\left|\lambda_{c}^{-}\right|=$ $\left|\lambda_{c}^{+}\right|$. If borrowing constraints limit the degree to which consumption can be smoothed, then negative output shocks should be mirrored in consumption sooner than positive shocks and therefore we expect $\left|\lambda_{c}^{-}\right|>\left|\lambda_{c}^{+}\right|$in this case.

Furthermore, if borrowing constraints limit the amount of consumption smoothing after negative shocks then it appears conceivable that consumption is particularly exposed to large adverse shocks. That is, constraints may be particularly tight if countries have to borrow large amounts. To capture this idea, we introduce an additional set of dummy variables which take the size of the deviation from average output growth into account: $S_{i t}^{0}=1$ if $\Delta \tilde{y}_{i .}-\sigma<\Delta \tilde{y}_{i t}<\Delta \tilde{y}_{i}+\sigma$ and $S_{i t}^{0}=0$ otherwise, where $\Delta \tilde{y}_{i}$. is the average change in idiosyncratic output in country $i$ and $\sigma$ its standard deviation over the sample period. Similarly, $S_{i t}^{-}=1$ if $\Delta \tilde{y}_{i t}<\Delta \tilde{y}_{i .}-\sigma$ and $S_{i t}^{-}=0$ otherwise, and $S_{i t}^{+}=1$ if $\Delta \tilde{y}_{i t}>\Delta \tilde{y}_{i .}+\sigma$ and $S_{i t}^{+}=0$ otherwise. Thus, this set of dummy variables distinguishes between times of roughly average 
or normal output growth and episodes of relatively low and high growth, where we consider values of $\Delta \tilde{y}_{i t}$ which fall within one standard deviation around the average change as normal. ${ }^{3}$

Note that the dummy variables we introduce are defined with respect to short-run deviations from average growth. Hence, this classification cannot be used to separate countries according to the level of risk sharing they can achieve in the long run. Therefore, we restrict the $\beta$ coefficient in (1) to be the same in all countries. This assumption is justified as the Hausman-test carried out by Leibrecht and Scharler (2008), using the same data and same specification, does not reject the null hypothesis of a common long-run degree of international consumption risk sharing. Intuitively, the homogeneity with respect to $\beta$ implies that in the long run any restrictions that limit the amount of risk sharing have rather similar implications across countries.

To empirically implement (2) we follow the methodology outlined in Engle and Granger (1987). First, we estimate the long-run relationship in (1), and second, we estimate (2) and (3) by Seemingly Unrelated Regressions. ${ }^{4}$ A 'general-to-specific'- approach is used to derive a parsimonious model. We thereby apply the sequential general-to-specific testing strategy proposed by Hall (1994) and recommended by Maddala and Kim (1998) to each single equation and each variable. We start with a lag of $T^{1 / 3}$ (see Said and Dickey, 1984) and test down until the lag is statistically significant at the 10 percent significance level.

\footnotetext{
${ }^{3}$ In principle, we can also identify periods characterized by more extreme deviations by using e.g. two standard deviations. However, since such periods rarely occur, we would not have enough observations for statistically identifying the effect.

${ }^{4}$ Our approach requires the series to be cointegrated. Since evidence in favor of cointegration has already been reported in Leibrecht and Scharler (2008) for our data set, we start directly with the estimation of the ECM.
} 


\section{Data and Estimation Results}

\subsection{Data Description}

In our analysis, we include 21 OECD countries: Australia, Austria, Belgium, Canada, Denmark, Finland, France, Greece, Ireland, Italy, Japan, Luxembourg, the Netherlands, Norway, New Zealand, Portugal, Spain, Sweden, Switzerland, the UK and the US. The remaining OECD countries are not included due to limited data availability. Data are annual and range from 1951 to 2000. All series are obtained from the Penn World Table, release 6.1 by Heston et al. (2002). We use real per capita consumption and real per capita GDP measured in constant (1996) international prices as proxies for $\tilde{c}_{i t}$ and $\tilde{y_{i t}}$. World aggregates are calculated as weighted averages: $y_{t}=\sum_{i=1 \neq j}^{21} w_{i t} y_{i t}$ and $c_{t}=\sum_{i=1 \neq j}^{21} w_{i t} c_{i t}$, with $w_{i t}=p_{o p} p_{i t} / \sum_{i=1 \neq j}^{21} p o p_{i t}$, where $\operatorname{pop}_{i t}$ denotes population. Thus, $c_{i t}$ and $y_{i t}$ themselves are not included in the world aggregate.

Table 1 provides an overview of the deviations from average output growth in our sample. Columns 2 and 3 of the table show the number of years characterized by above and below average output growth which correspond to the definitions of $D_{i t}^{+}$and $D_{i t}^{-}$. The remaining columns correspond to the definitions of $S_{i t}^{0}, S_{i t}^{-}$and $S_{i t}^{+}$.

Not surprisingly, the first two columns show that the numbers of above and below average growth rates are rather balanced. Moreover, years with above and below average output growth are experienced at the end of our sample period. Notable exceptions are Ireland, Finland and the United States were the last episodes of below average growth rates were experienced in earlier years, indicating the relatively favorable macroeconomic performance of these countries in the last years. Italy and Japan, in contrast, saw their last above average growth rates in 1995 and 1991, respectively, which corresponds to the weak performance these two countries experienced in the second half of the 1990s. From the last three columns we see that the 
vast majority of years represent periods of 'normal' output growth, whereas periods where growth is at least one standard deviation above or below the average occur relatively rarely. Thus, the definitions of $S_{i t}^{-}$and $S_{i t}^{+}$capture rather extreme events. Such extreme events occurred, for instance, in the Scandinavian countries (Denmark, Sweden and Finland) which experienced severe economic downturns around 1990. Ireland and Luxembourg, in contrast, experienced relatively high growth rates in the late 1990s, which may be due to substantial gains from the European common market.

[Table 1 here ]

\section{$3.2 \quad$ Results}

Table 2 shows the estimated parameters of the long-run relationship (1). Estimates are based on the country fixed effects estimator (FE) as well as on the fully-modified OLS (FMOLS) estimator of Pedroni (2000) which allows us to conduct valid inference. We see that $\tilde{y}_{i t}$ enters strongly significantly with a point estimate of about 0.900. As discussed in Asdrubali et al. (1996) such an estimate implies that only around 10 percent of idiosyncratic risks are pooled in the long run. Thus, we find that long-run risk sharing is rather limited, which is in line with the literature cited above.

\section{[Table 2 here]}

Next, we estimate the ECM in (2) - (3). The testing down procedure shows that relatively parsimonious models are sufficient to capture the shortrun dynamics. The results based on our final specification are reported in Table 3. The top panel of the table shows the estimation results for the consumption equation (2). First of all, we see that $\Delta \tilde{c}_{i t}$ responds significantly to $\Delta \tilde{y}_{i t-1}$ which is inconsistent with perfect risk sharing since any influence of idiosyncratic variables - even lagged - should be completely eliminated under perfect risk sharing. 
What we are primarily interest in are the speed-of-adjustment coefficients in the consumption equation. From Table 3 we see that the point estimates for $\lambda_{c}^{+}$and $\lambda_{c}^{-}$are both significantly negative which shows that consumption growth reacts to deviations from the long-run relationship in times of below and also above average output growth. Comparing the magnitudes of the estimated speed-of-adjustment coefficients shows that $\tilde{c}_{i t}$ reacts more strongly to deviations from the long-run relationship when output growth is below average output growth. In this case, the estimated speedof-adjustment coefficient is -0.150 . In the case that $\Delta \tilde{y}_{i t}>\Delta \tilde{y}_{i}$, we estimate the speed-of-adjustment coefficient to be -0.094 . The null hypothesis that the speed-of-adjustment coefficients are equal is marginally rejected at the 10 percent significance level. The estimated coefficients of -0.094 and -0.150 translate into mean adjustment lags of 10.5 and 6.5 years in case of negative and positive income shocks. ${ }^{5}$ Thus, these results provide first evidence in favor of our hypothesis that borrowing constraints become binding soon after negative income shocks. Intuitively, when countries experience adverse shocks to their idiosyncratic output growth rates, then their consumption growth mirrors output growth closely already after a relatively short period of time.

The lower panel of Table 3 shows the results for the output equation (3). We see that three of its own lags are sufficient to capture the short run dynamics of idiosyncratic output growth $\Delta \tilde{y}_{i t}$. The table also shows that the response of $\Delta \tilde{y}_{i t}$ is only significantly different from zero in the case of positive deviations. Nevertheless the null that $\lambda_{y}^{-}=\lambda_{y}^{+}=0$ is rejected at the 10 percent level. Hence, $\Delta \tilde{y}_{i t}$ cannot be considered to be weakly exogenous in our system. Thus, consumption as well as output respond to shocks to restore the long-run relationship. Note that direct convergence to the long-run relationship occurs if $\lambda_{c}$ is negative and $\lambda_{y}$ is positive. We find,

\footnotetext{
${ }^{5}$ The mean adjustment lags are calculated as $1 /\left|\lambda_{c}^{+}\right|$and $1 /\left|\lambda_{c}^{-}\right|$, respectively.
} 
however, that $\lambda_{y}^{+}$turns out to be significantly below zero. Nevertheless, the system is stable since $\left|\lambda_{c}\right|>\left|\lambda_{y}\right|$ (see Juselius, 2006).

[Table 3 here]

Next, we characterize risk sharing not only according to the sign of the deviation from average output growth, but also according to the size of the deviation. We re-estimate the ECM in (2) - (3) but now we parameterize $\lambda_{k}=\lambda_{k}^{-} S_{i t}^{-}+\lambda_{k}^{0} S_{i t}^{0}+\lambda_{k}^{+} S_{i t}^{+}$, for $k=c, y$.

Table 4 shows that we obtain the lowest speed-of-adjustment coefficient in the consumption equation of -0.216 for the case where output growth is at least one standard deviation below average output growth. For values of $\Delta \tilde{y}_{i t}$ which are close to the average $\Delta \tilde{y}_{i}$. we obtain a markedly higher speed-of-adjustment coefficient of -0.111 and therefore a slower adjustment of consumption growth. A similar speed-of-adjustment is implied by the estimate for $\lambda_{c}^{+}$of -0.097 which is associated with output growth rates that are at least one standard deviation above average output growth. Most importantly however, $\lambda_{c}^{-}$is significantly different from both, $\lambda_{c}^{0}$ and $\lambda_{c}^{+}$at the 5 and 10 percent significance level. The implied mean adjustment lags are about 4, 9 and 10 years respectively. Experiencing a pronounced negative output shock results in a much faster return to the long-run equilibrium than experiencing a negative, yet 'normal', or a positive deviation from average growth. Thus, the ordering of the estimated speed-of-adjustment coefficients is again consistent with our hypothesis. Note also that our results imply that consumption growth responds rather similarly after marked positive shocks and in normal periods.

Turning to the results for the output equation in the lower panel of the table, we again see that $\Delta \tilde{y}_{i t}$ reacts significantly only in the case of positive deviations. As before, the null of joint insignificance of the speedof-adjustment coefficients in (3) is rejected and the system is stable. 
[Table 4 here]

\subsection{Financial Globalization and the Adjustment Process}

Over the last decades, international financial markets have become increasingly liberalized and integrated. Several papers show that financial integration increases the international sharing of consumption risk (see e.g. Imbs, 2006; Sørensen et al., 2005). Therefore, in this section, we study how the adjustment after shocks has changed over time along with the ongoing process of the globalization of financial markets. More specifically, we split our sample in 1980 and re-estimate the long-run relationship (1) as well as the ECM in (2) and (3) for the two resulting subsamples. The choice of the date at which we split the sample is motivated by Artis and Hoffmann (2008) who argue that since the beginning of the 1980s, the higher integration of international financial markets has resulted in higher international risk sharing.

We first test for cointegration between $\tilde{c}_{i t}$ and $\tilde{y}_{i t}$ in the two subsamples using the panel cointegration test of Pedroni (1999). Table 5 shows that the vast majority of the tests reject the null hypothesis of no cointegration for both time periods. Thus, we may conclude that $\tilde{c}_{i t}$ and $\tilde{y}_{i t}$ are cointegrated in both subsamples.

[Table 5 here]

Table 6 shows the coefficients for the long-run relationship in (1) estimated over the two subsamples. As expected, the long-run exposure of consumption growth to idiosyncratic output growth has declined. Thus, we find that long-run risk sharing improved, although the extent of risk sharing still remains low. Overall, these findings are in line with Artis and Hoffmann (2008), who also document an increase in risk sharing over time.

[Table 6 here] 
Table 7 shows the results for equation (2) with $\Delta \tilde{c}_{i t}$ as the dependent variable. ${ }^{6}$ We include two lags of the consumption growth rate in both subsamples, whereas lagged values of the output growth rate are only included in the first subsample. In the later subsample, lagged values of consumption growth are sufficient to capture the short-term dynamics as indicated by our testing down strategy.

Turning to the speed-of-adjustment coefficients we see that $\lambda^{+}$and $\lambda^{-}$ are significantly different from zero in both subsamples. Note that in the period 1950 - 1979 the null of an equal speed-of-adjustment, $\lambda^{+}=\lambda^{-}$cannot be rejected. Recall, however, from the discussion in Section 2 that a symmetric adjustment process does not allow for an unambiguous interpretation in terms of the relevance of borrowing constraints. The symmetric adjustment during the first subsample may simply indicate that most countries in our sample faced severe constraints. This interpretation is also consistent with the negligible extent of long-run of risk sharing we find for the period prior to 1980.

[Table 7 here]

After 1980, however, we find evidence in favor of an asymmetric adjustment. Table 7 shows that the null hypothesis of equal speed-of-adjustment coefficients is rejected at the 5 percent significance level. Hence, consumption adjusts significantly faster after negative shocks which indicates that borrowing constraints are relevant and do not allow to postpone the impact of adverse shocks for longer periods of time. Our estimates imply a mean adjustment lag of 5 years if output growth is above average, whereas the mean adjustment lag is only 3 years when output growth is below aver-

\footnotetext{
${ }^{6}$ Note that we only report the estimation results for the case where the speed-ofadjustment coefficient depends on the sign of the deviation of idiosyncratic output growth from its average but not on the size of the deviation. Taking the size of the deviation into account leaves our conclusions qualitatively unaffected. Also note that the system is stable in both time periods. However, to preserve space we do not report the results for (3) estimated over the subsamples. Detailed estimation results are available upon request.
} 
age. Thus, the asymmetric speed-of-adjust is in line with the interpretation that the low degree of risk sharing may be due to borrowing constraints on international financial markets.

\section{Concluding Remarks}

In this paper we analyze whether the adjustment process of consumption growth after disequilibrating output shocks depends on the sign of the shock. We indeed find evidence in this respect, especially since 1980. The longrun equilibrium is restored relatively quickly after adverse output shocks, whereas consumption growth adjusts slower after positive output shocks. Thus, countries are able to smooth the impact of adverse shocks only to a comparably limited extent. One explanation is that borrowing constraints on international financial markets reduce the opportunities to smooth adverse output effects.

It has to be pointed out that borrowing constraints are perhaps not the only source of asymmetric adjustment in consumption. However, since it is well documented in the literature that risk sharing occurs primarily via the adjustment of asset holdings, frictions on international credit markets that result in borrowing constraints are likely to play a non-negligible role.

\section{References}

Altonji, J. G., Siow, A., 1987. Testing the response of consumption to income changes with (noisy) panel data. The Quarterly Journal of Economics 102 (2), 293-328.

Artis, M., Hoffmann, M., 2008. Financial globalization, international business cycles and consumption risk sharing. Scandinavian Journal of Economics 110 (3), 447-471.

Asdrubali, P., Sørensen, B. E., Yosha, O., 1996. Channels of interstate risk 
sharing: The United States 1963-1990. Quarterly Journal of Economics 111, 1081-1110.

Backus, D. K., Kehoe, P. J., Kydland, F. E., 1992. International real business cycles. Journal of Political Economy 100, 745-775.

Baxter, M., Crucini, M. J., 1995. Business cycles and the asset structure of foreign trade. International Economic Review 36, 821-854.

Becker, S. O., Hoffmann, M., 2006. Intra- and international risk-sharing in the short run and the long run. European Economic Review 50 (3), 777-806.

Borge, L.-E., Matsen, E. M., 2004. Public employment and regional risk sharing. Scandinavian Journal of Economics 106 (2), 215-230.

Buettner, T., 2002. Fiscal federalism and interstate risk sharing: empirical evidence from Germany. Economics Letters 74, 195-202.

Canova, F., Ravn, M. O., 1996. International consumption risk sharing. International Economic Review 37, 573-601.

Engle, R. F., Granger, C. W. J., 1987. Co-integration and error correction: Representation, estimation, and testing. Econometrica 55 (2), 251-276.

Hall, A., 1994. Testing for a unit root in time series with pretest data-based model selection. Journal of Business and Economic Statistics 12 (4), 461470.

Heston, A., Summers, R., Aten, B., 2002. Penn world table version 6.1. Center for International Comparisons at the University of Pennsylvania (CICUP).

Hoffmann, M., 2008. The lack of international consumption risk sharing: Can inflation differentials and trading costs help explain the puzzle? Open Economies Review 19 (2), 183-201. 
Imbs, J., 2006. The real effects of financial integration. Journal of International Economics 68 (2), 296-324.

Juselius, K., 2006. The Cointegrated VAR Model: Methodology and Applications. Oxford University Press, Great Clarendon Street, Oxford.

Leibrecht, M., Scharler, J., 2008. International risk sharing in the OECD: Some evidence based on panel cointegration. Open Economies Review forthcoming.

Lewis, K., 1999. Trying to explain home bias in equities and consumption. Journal of Economic Literature XXXVII, 571-608.

Lewis, K. K., 1996. What can explain the apparent lack of international consumption risk sharing. Journal of Political Economy 104, 267-297.

Maddala, G., Kim, I.-M., 1998. Unit roots, Cointegration, and Structural Change. Cambridge University Press, Trumpington Street, Cambridge.

Obstfeld, M., 1994. Are industrial-country consumption risks globally diversified? In: Leiderman, L., Razin, A. (Eds.), Capital mobility: the impact on consumption, investment and growth. Cambridge University Press, Cambridge.

Obstfeld, M., Rogoff, K., 2000. The six major puzzles in international macroeconomics. In: Bernanke, B. S., Rogoff, K. (Eds.), NBER Macroeconomic Annual 2000. MIT Press, Cambridge, Massachusetts.

Pedroni, P., 1999. Critical values for cointegration tests in heterogeneous panels with multiple regressors. Oxford Bulletin of Economics and Statistics $61(4), 653-670$.

Pedroni, P., 2000. Fully-modified OLS for heterogeneous cointegrated panels. Advances in Econometrics 15, 93-130. 
Said, E., Dickey, D. A., 1984. Testing for unit roots in autoregressive-moving average models of unknown order. Biometrika 71 (3), 599-607.

Scorcu, A. E., 1998. Consumption risk-sharing in Italy. Applied Economics 30 (1), 407-414.

Shea, J., 1995a. Myopia, liquidity constraints, and aggregate consumption: A simple test. Journal of Money, Credit and Banking 27 (3), 798-805.

Shea, J., 1995b. Union contracts and the life-cycle/permanent-income hypothesis. American Economic Review 85 (1), 186-200.

Sørensen, B. E., Wu, Y.-T., Yosha, O., Zhu, Y., 2005. Home bias and international risk sharing: Twin puzzles separated at birth. CEPR Discussion Papers 5113.

Sørensen, B. E., Yosha, O., 1999. International risk sharing and European monetary unification. Journal of International Economics 45, 211-238.

Stockman, A. C., Tesar, L., 1995. Tastes and technology in a two-country model of the business cycle: explaining international comovements. American Economic Review 85, 168-185. 
Table 1: Deviations from average output growth

\begin{tabular}{rrrrrr}
\hline \hline & below & above & positive & negative & normal \\
\hline Australia & $22(2000)$ & $27(1999)$ & $3(1958)$ & $9(1990)$ & 37 \\
Austria & $28(2000)$ & $21(1998)$ & $7(1974)$ & $4(1984)$ & 38 \\
Belgium & $24(1998)$ & $25(2000)$ & $6(1991)$ & $8(1993)$ & 35 \\
Canada & $19(1996)$ & $30(2000)$ & $4(1999)$ & $11(1991)$ & 34 \\
Switzerland & $28(1999)$ & $21(2000)$ & $8(1989)$ & $4(1976)$ & 37 \\
Denmark & $29(1999)$ & $20(2000)$ & $11(1994)$ & $5(1989)$ & 33 \\
Spain & $23(2000)$ & $26(1999)$ & $4(1995)$ & $6(1996)$ & 39 \\
Finland & $23(1993)$ & $26(2000)$ & $7(1982)$ & $7(1992)$ & 35 \\
France & $28(2000)$ & $21(1998)$ & $9(1982)$ & $4(1993)$ & 36 \\
Greece & $27(1999)$ & $23(2000)$ & $8(1994)$ & $5(1981)$ & 36 \\
Ireland & $23(1986)$ & $22(2000)$ & $12(1975)$ & $7(1987)$ & 30 \\
Italy & $24(2000)$ & $25(1995)$ & $8(2000)$ & $10(1986)$ & 31 \\
Japan & $25(2000)$ & $24(1991)$ & $9(1970)$ & $6(1900)$ & 31 \\
Luxembourg & $26(1996)$ & $23(2000)$ & $9(1997)$ & $5(1975)$ & 34 \\
Netherlands & $24(2000)$ & $25(1999)$ & $5(1991)$ & $6(1981)$ & 38 \\
Norway & $23(2000)$ & $26(1997)$ & $4(1993)$ & $10(1999)$ & 35 \\
New Zealand & $23(1998)$ & $26(2000)$ & $6(1991)$ & $5(1977)$ & 38 \\
Portugal & $24(2000)$ & $25(1999)$ & $6(1991)$ & $7(1994)$ & 36 \\
Sweden & $24(1997)$ & $25(2000)$ & $7(1982)$ & $8(1993)$ & 34 \\
United States & $23(1991)$ & $26(2000)$ & $2(1984)$ & $10(1981)$ & 37 \\
\hline \hline
\end{tabular}

Notes: The columns labeled 'below' and 'above' report the number of periods in which real per capita GDP growth was either below or above the average growth rate. In brackets we report the last year when a positive or negative deviation occurred. The columns labeled "positive', "negative" and "normal" report the number of years in which real per capita GDP growth was at least one standard deviation blow average growth, at least one standard deviation above average growth and within plus/minus one standard deviation of the average growth rate, respectively. In brackets, we report the last year when the respective deviation occurred.

Table 2: Long-run Relationship

\begin{tabular}{lccc}
\hline \hline Dep. Var.: $\tilde{c}_{i t}$ & coef & sd & p-value \\
\hline FE & 0.904 & n.a. & n.a. \\
FMOLS & 0.900 & 0.02 & 0.000 \\
\hline obs & 1050 & & \\
\hline \hline
\end{tabular}

Notes: The table shows the estimated coefficient of $\tilde{y}_{i t}$ in the long-run relationship, based on the country fixed effects estimator (FE) and the fully-modified OLS (FMOLS) estimator. Common time effects are subtracted (results with common time effects not subtracted are qualitatively similar). 
Table 3: Asymmetric Error-Correction

\begin{tabular}{lccc}
\hline \hline Dep. Var.: $\Delta \tilde{c}_{i t}$ & coef & sd & p-value \\
\hline$\Delta \tilde{y}_{i t-1}$ & 0.104 & 0.041 & 0.011 \\
$\lambda_{c}^{+}$ & -0.094 & 0.023 & 0.000 \\
$\lambda_{c}^{-}$ & -0.150 & 0.023 & 0.000 \\
\hline obs & 966 & & \\
$H_{0}: \lambda_{c}^{+}=\lambda_{c}^{-}$ & & & 0.089 \\
\hline Dep. Var.: $\Delta \tilde{y}_{i t}$ & coef & sd & p-value \\
\hline$\Delta \tilde{y}_{i t-1}$ & 0.190 & 0.030 & 0.000 \\
$\Delta \tilde{y}_{i t-2}$ & -0.012 & 0.027 & 0.643 \\
$\Delta \tilde{y}_{i t-3}$ & 0.058 & 0.006 & 0.024 \\
$\lambda_{y}^{+}$ & -0.036 & 0.017 & 0.035 \\
$\lambda_{y}^{-}$ & -0.009 & 0.017 & 0.577 \\
\hline obs & 966 & & \\
$H_{0}: \lambda_{y}^{+}=\lambda_{y}^{-}=0$ & & & 0.091 \\
\hline \hline
\end{tabular}

Notes: The top panel of the table reports estimated coefficients for the error correction model with $\Delta \tilde{c}_{i t}$ as the dependent variable. The bottom panel reports the results for $\Delta \tilde{y}_{i t}$ as the dependent variable. Country dummies are jointly significant and therefore included in the estimation.

Table 4: Asymmetric Error-Correction and Large Deviations

\begin{tabular}{lccc}
\hline \hline Dep. Var.: $\Delta \tilde{c}_{i t}$ & coef & sd & p-value \\
\hline$\Delta \tilde{y}_{i t-1}$ & 0.100 & 0.042 & 0.016 \\
$\lambda_{c}^{0}$ & -0.111 & 0.019 & 0.000 \\
$\lambda_{c}^{+}$ & -0.097 & 0.044 & 0.028 \\
$\lambda_{c}^{-}$ & -0.216 & 0.046 & 0.000 \\
\hline obs & 966 & & \\
$H_{0}: \lambda_{c}^{+}=\lambda_{c}^{-}$ & & & 0.062 \\
$H_{0}: \lambda_{c}^{0}=\lambda_{c}^{-}$ & & & 0.034 \\
\hline Dep.Var: $\Delta \tilde{y}_{i t}$ & coef & sd & p-value \\
\hline$\Delta \tilde{y}_{i t-1}$ & 0.185 & 0.031 & 0.000 \\
$\Delta \tilde{y}_{i t-2}$ & -0.011 & 0.026 & 0.678 \\
$\Delta \tilde{y}_{i t-3}$ & 0.058 & 0.026 & 0.024 \\
$\lambda_{y}^{0}$ & -0.019 & 0.014 & 0.177 \\
$\lambda_{y}^{+}$ & -0.072 & 0.033 & 0.027 \\
$\lambda_{y}^{-}$ & 0.008 & 0.033 & 0.822 \\
\hline obs & 966 & & \\
$H_{0}: \lambda_{y}^{+}=\lambda_{y}^{-}=\lambda_{y}^{0}=0$ & & & 0.078 \\
\hline \hline
\end{tabular}

Notes: The top panel of the table reports estimated coefficients for the error correction model with $\Delta \tilde{c}_{i t}$ as the dependent variable. The bottom panel reports the results for $\Delta \tilde{y}_{i t}$ as the dependent variable. Country dummies are jointly significant and therefore included in the estimation. 
Table 5: Pedroni Cointegration Tests

\begin{tabular}{lll}
\hline \hline & $1951-1979$ & $1980-2000$ \\
\cline { 2 - 3 } panel- $\nu$ & $3.337^{* * *}$ & $1.837^{* *}$ \\
panel- $\rho$ & $-3.249^{* * *}$ & $-1.419^{*}$ \\
panel-pp & $-3.149^{* * *}$ & $-1.742^{* *}$ \\
panel-adf & $-2.652^{* * *}$ & $-2.402^{* * *}$ \\
group- $\rho$ & $-1.855^{* *}$ & 0.817 \\
group-pp & $-3.444^{* * *}$ & -0.275 \\
group-adf & $-2.192^{* *}$ & $-1.794^{* *}$ \\
\hline \hline
\end{tabular}

Notes: Based on one-sided, unweighed tests with common time effects subtracted (tests with common time effects not subtracted show similar results). All test statistics follow asymptotically standard normal distribution under the null of unit root or no cointegration ${ }^{* * *(*)[*]}$ stands for $1 \%(5 \%)[10 \%]$.

Table 6: Long-Run Risk Sharing before and after 1980

\begin{tabular}{lcccccc}
\hline \hline & \multicolumn{3}{c}{$1950-1979$} & \multicolumn{3}{c}{$1980-2000$} \\
\cline { 2 - 7 } Dep. Var.: & coef & sd & p-value & coef & sd & p-value \\
\hline FE & 0.850 & n.a & n.a & 0.690 & n.a & n.a. \\
FMOLS & 0.940 & 0.016 & 0.000 & 0.780 & 0.041 & 0.000 \\
\hline obs & 609 & & & & 441 & \\
\hline \hline
\end{tabular}

Notes: The table shows the estimated coefficient of $\tilde{y}_{i t}$ in the long-run relationship, based on the country fixed effects estimator (FE) and the fully-modified OLS (FMOLS) estimator. Common time effects are subtracted (results with common time effects not subtracted are qualitatively similar). 


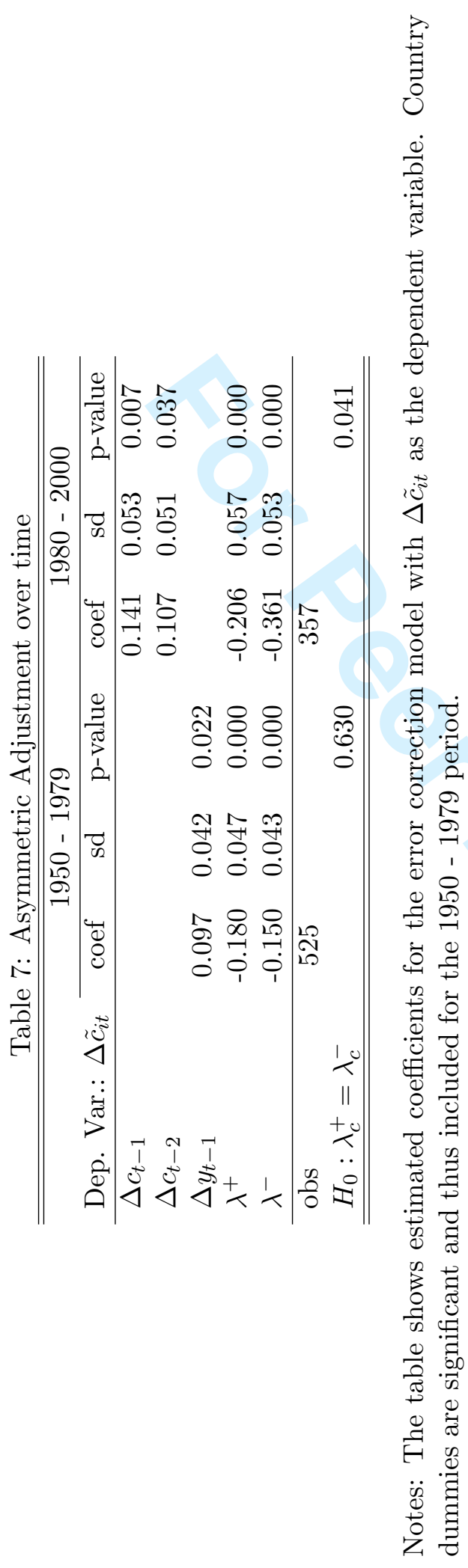

